\title{
Clinical characteristics and outcomes of pregnant women with COVID-19 and the risk of vertical transmission: a systematic review
}

\author{
Jianhua $\mathrm{Chi}^{1,2} \cdot$ Wenjian Gong ${ }^{1,2} \cdot$ Qinglei Gao ${ }^{1,2} \mathbb{D}$
}

Received: 1 June 2020 / Accepted: 6 November 2020 / Published online: 1 December 2020

(C) The Author(s) 2020

\begin{abstract}
Purpose This systematic review summarizes the clinical features and maternal-infant outcomes of 230 pregnant women (154 patients gave birth) infected with COVID-19 and their 156 infants, including the possibility and evidence of vertical transmission.

Methods An electronic search of PubMed, Embase, Medline, MedRxiv, CNKI, and the Chinese Medical Journal Full Text Database following PRISMA guidelines was performed through April 18, 2020. Search terms included COVID-19, SARSCoV-2, pregnant women, infants, and vertical transmission.

Results A total of 230 women with COVID-19 (154 deliveries, 66 ongoing pregnancies, and 10 abortions) and 156 newborns from 20 eligible studies were included in this systematic review. A total of $34.62 \%$ of the pregnant patients had obstetric complications, and $59.05 \%$ of patients displayed fever. Lymphopenia was observed in $40.71 \%$ of patients. A total of $5.19 \%$ of women received mechanical ventilation. Seven women were critically ill. One mother and two newborns died. A total of $24.74 \%$ of newborns were premature. Five newborns' throat swab tests of SARS-CoV-2 were positive, all of which were delivered by cesarean section. For eight newborns with negative throat swab tests, three had both elevated IgM and IgG against SARS-CoV-2. Nucleic acid tests of vaginal secretions, breast milk, amniotic fluid, placental blood, and placental tissues were negative.

Conclusion Most pregnant patients were mildly ill. The mortality of pregnant women with COVID-19 was lower than that of overall COVID-19 patients. Cesarean section was more common than vaginal delivery for pregnant women with COVID19. Premature delivery was the main adverse event for newborns. The vertical transmission rate calculated by SARS-CoV-2 nucleic acid tests was 3.91\%. Serum antibodies against SARS-CoV-2 should be tested more frequently, and multiple samples should be included in pathogenic testing.
\end{abstract}

Keywords COVID-19 $\cdot$ Delivery $\cdot$ Infants $\cdot$ Pregnancy $\cdot$ SARS-CoV-2 $\cdot$ Vertical transmission

Jianhua Chi and Wenjian Gong have contributed equally to this work.

\section{Qinglei Gao}

qingleigao@hotmail.com

1 Cancer Biology Research Center (Key Laboratory of the Ministry of Education), Tongji Hospital, Tongji Medical College, Huazhong University of Science and Technology, 1095 Jiefang Ave, Wuhan, Hubei, China

2 Department of Gynecology and Obstetrics, Tongji Hospital, Tongji Medical College, Huazhong University of Science and Technology, Wuhan, Hubei, China

\section{Introduction}

Coronavirus disease 2019 (COVID-19), caused by severe acute respiratory syndrome coronavirus 2 (SARS-CoV-2), was characterized as a pandemic by the World Health Organization on March 11, 2020 [1]. It is believed that pregnant women are more susceptible to virus infections due to immunologic and anatomic alterations [2]. Pregnant women with severe acute respiratory syndrome (SARS) or middle east respiratory syndrome (MERS) have serious adverse outcomes, such as maternal deaths and premature births, while no evidence of vertical transmission has been found [3]. As more articles have described the clinical characteristics and outcomes of pregnant women with COVID-19, our 
understanding of how COVID-19 may influence pregnant women continues to improve. This systematic review aims to summarize the clinical characteristics and maternal-infant outcomes of pregnant women with COVID-19, especially the possibility of vertical transmission.

\section{Methods}

\section{Search strategy and selection criteria}

An electronic search of PubMed, Embase, Medline, MedRxiv, CNKI (China National Knowledge Infrastructure), and the Chinese Medical Journal Full Text Database (http:// journal.yiigle.com/) was performed following Preferred Reporting Items for Systematic reviews and Meta-Analyses (PRISMA) guidelines [4] through to April 18, 2020. Search terms were (COVID-19 OR 2019-nCoV OR SARS-CoV-2 OR 2019 Novel coronavirus) AND (pregnant women OR Maternal OR parturient OR mothers OR Infant OR Newborn OR neonate OR Infectious Disease Transmission, Vertical).

The titles and abstracts in the search results were independently reviewed by two authors (Jianhua Chi and Wenjian Gong) to determine whether the article was relevant to our research topic. The full texts of the literature we identified were further searched, and we read the articles to identify those eligible that ultimately met the inclusion and exclusion criteria. The inclusion criteria were as follows: 1, pregnant women were diagnosed with COVID-19 by dual fluorescence polymerase chain reaction (PCR) or quantitative real-time polymerase chain reaction (qRT-PCR), or were clinically diagnosed cases according to the latest clinical guidelines at the time of the article's publication; 2 , articles that described clinical characteristics and maternal and newborn outcomes. The exclusion criteria included, 1 , duplicated cases and 2, newborns who tested positive for COVID-19 but lived with COVID-19 relatives to avoid confounding factors when assessing vertical transmission. We abandoned duplicated cases by referring to the birthplace, times of admission and delivery, specific maternal characteristics of cases, as well as dates and authors of publications to eliminate potential overlap of cases.

\section{Data extraction, assessment of risk of bias, and data synthesis}

The following variables were extracted from eligible literature: study type, time, region, inclusion criteria, sample size, epidemiological history of mothers and newborns related to COVID-19, delivery mode (cesarean section/vaginal delivery), cesarean section indications, fetal sex (male/female), gestational age, birth weight, clinical diagnosis, imaging, oxygen therapy, antiviral treatment, breastfeeding, maternal and newborn outcomes, case admission time and hospital name, number of pregnant women, clinical characteristics and outcomes of pregnant women, number of newborns, characteristics and outcomes, method of diagnosis and number of positive diagnoses. To avoid bias, the authors received training, established a consensus, read all articles separately, and discussed any ambiguities.

We adopted an approach specially used for case reports and case series that was proposed by Murad et al. [5] to evaluate the quality of the included articles. According to this method, two authors read all articles and considered four aspects, selection, ascertainment, causality, and reporting.

\section{Results}

\section{Study selection and characteristics}

A preliminary search returned 538 articles. After reading the titles and abstracts, 60 articles were chosen, and the others were inconsistent with our research topic. After we read the full texts, twenty articles were ultimately included [6-25] (Table 1). Twenty-five articles were excluded because of duplicated cases; nine articles were excluded because newborns tested positive for COVID-19 had contacts with confirmed COVID-19 patients; two articles were excluded because the department of anesthesiology published a paper in which we suspected that these cases had appeared in other papers; and four articles were excluded because they were not related to parturition. The flow chart of publication selection is shown in Fig. 1. Eligible articles were mainly case reports and case series. The cases predominantly occurred around February 2020.

Quality evaluation of all articles was performed according to several key questions [5]. For study selection, whether it was a case report or case series, each author collected the cases of which they were aware in their hospital, so the overall quality of this item was good. In the domain 'ascertainment', each case was diagnosed according to the latest clinical guidelines, so the overall quality of this item was the best. In terms of causality, these articles were mainly descriptive studies, so the overall quality was low. In the final domain of 'reporting', most articles provided as many details as possible, so the quality was good.

\section{Synthesis of the results}

\section{Maternal characteristics and outcomes}

A total of 230 pregnant women with COVID-19 were included (Table 2). Five of them decided to terminate their pregnancy, four of which had induced abortions owing to the concerns about COVID-19. Three pregnant women had 
Table 1 Background characteristics of the selected studies

\begin{tabular}{|c|c|c|c|c|c|}
\hline & Authors & Study date & Study location & Study design & Pregnancies \\
\hline 1 & Zengyuan Yu et al. [6] & 31 January, 2020 & Zhengzhou, China & Case report & 1 \\
\hline 2 & Ruihong Zhao et al. [7] & 19 January, 2020 & Hangzhou, China & Case report & 1 \\
\hline 3 & Siyu Chen et al. [8] & 20 January to 10 February, 2020 & Wuhan, China & Retrospective cohort & 5 \\
\hline 4 & Dong Hwan Lee et al. [9] & 19 January, 2020 & Daegu, Korea & Case report & 1 \\
\hline 5 & $\mathrm{Na} \mathrm{Li} \mathrm{et} \mathrm{al.} \mathrm{[10]}$ & 24 January to 29 February, 2020 & Wuhan, China & Case-control study & 16 \\
\hline 6 & Yang Li et al. [11] & 12 January, 2020 & Hangzhou, China & Case report & 1 \\
\hline 7 & Xiaotong Wang et al. [12] & 2 February, 2020 & Suzhou, China & Case report & 1 \\
\hline 8 & Zambrano LI et al. [13] & 9 March, 2020 & Tegucigalpa, Honduras & Case report & 1 \\
\hline 9 & Lingkong Zeng et al. [14] & January to February, 2020 & Wuhan, China & Retrospective cohort & 33 \\
\hline 10 & Mengdie Li et al. [15] & 29 January, 2020 & Xinyang, China & Case report & 1 \\
\hline 11 & Yiwei Zhao et al. [16] & 31 January, 2020 & Wenzhou, China & Case report & 1 \\
\hline 12 & Renbin Zhou et al. [17] & 12 February, 2020 & Yichun, China & Case report & 1 \\
\hline 13 & Siying Zhuang et al. [18] & 20 January, 2020 & Wuhan, China & Case report & 1 \\
\hline 14 & E. Kalafat et al. [19] & 20 March, 2020 & Ankara, Turkey & Case report & 1 \\
\hline 15 & Parisa Karami et al. [20] & 31 March, 2020 & Zanjan, Iran & Case report & 1 \\
\hline 16 & Xiali Xiong et al. [21] & 29 January, 2020 & Beijing, China & Case report & 1 \\
\hline 17 & Bin Zhang et al. [22] & 1 February, 2020 & Zhongshan, China & Case report & 1 \\
\hline 18 & Liquan Huang et al. [23] & 26 January, 2020 & Wuhan, China & Case report & 1 \\
\hline 19 & Lian Chen et al- [24] & 8 December, 2019 , to 20 March, 2020 & Wuhan, China & Retrospective cohort & 118 \\
\hline 20 & Noelle Breslin et al. [25] & 13 March to 17 March, 2020 & New York, American & Retrospective cohort & 43 \\
\hline
\end{tabular}

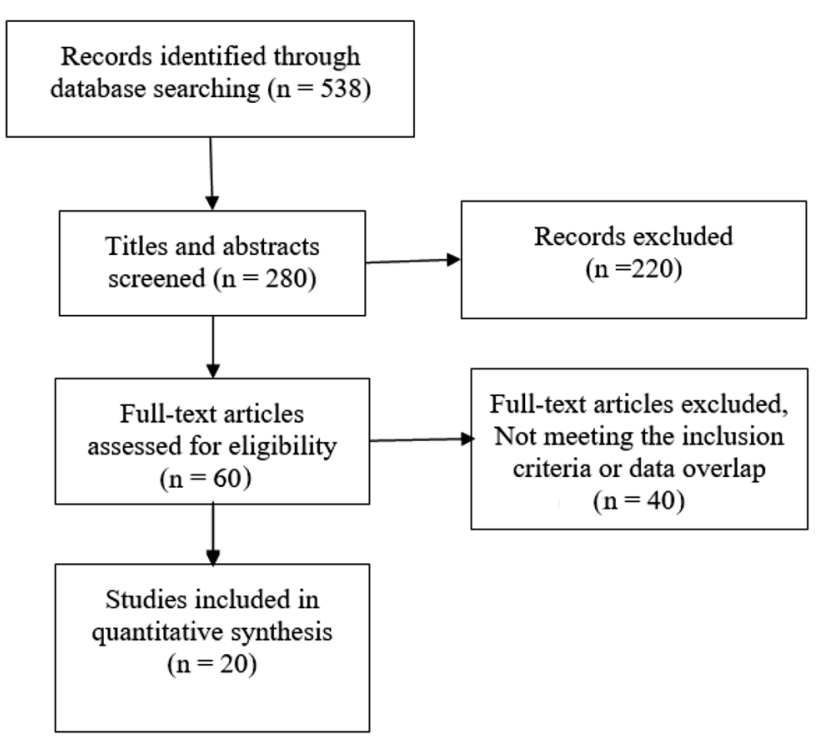

Fig. 1 PRISMA flowchart of included studies

spontaneous abortions, and two patients had ectopic pregnancies. A total of 154 pregnant women delivered, and 66 pregnant women continued their pregnancy. Among these pregnant women with COVID-19, 25.00\% of patients had chronic diseases, such as hypertension and polycystic ovary syndrome. A total of $34.62 \%$ of cases had obstetric complications, including anemia (31.58\%), gestational hypertension (13.41\%), preeclampsia (12.90\%), and gestational diabetes $(11.76 \%)$. The most common symptoms were fever (59.05\%) and cough (54.76\%), followed by postpartum fever (25.51\%) and physical discomfort (21.43\%). Myalgia, shortness of breath, headaches, and diarrhea were observed in $19(12.75 \%), 20(11.90 \%), 16(11.35 \%)$, and $8(5.06 \%)$ patients, respectively. For laboratory examinations, 57 (40.71\%) patients developed lymphopenia, and 21 (16.84\%) patients had leukocytosis. Platelet count was decreased in 5 (4.03\%) pregnant women. Concentrations of transaminase, C-reactive protein, and D-dimer were elevated in 26 (25\%), 83 (64.34\%), and 92 (82.14\%) patients, respectively. However, other parameters, though their significant prognostic values in COVID-19 were reported [26-28], were tested less frequently. Concentrations of procalcitonin (PCT), myocardial enzyme, and IL-6 were elevated in 5 (38.46\%), 4 (44.44\%), and 5 (100\%) pregnant women, respectively. Reports of these three parameters included less than $10 \%$ of patients, and these characteristics should be interpreted with caution because of possible bias. Imaging revealed pulmonary infection in $97.12 \%$ of the patients.

In terms of treatment, 7 (5.19\%) pregnant women received mechanical ventilation, and 67 (59.82\%) pregnant women received oxygen support through a nasal catheter. Most of the pregnant women received routine treatment, including antiviral drugs and antibiotics, to prevent infection. Only 7 (4.00\%) pregnant women were critically ill, $14(8.00 \%)$ women had severe cases, and $144(82.29 \%)$ 
Table 2 Maternal characteristics and outcomes

\begin{tabular}{|c|c|c|c|}
\hline & Case numbers & Total numbers & $\%$ \\
\hline \multicolumn{4}{|l|}{ Characteristics of patients } \\
\hline Cesarean delivery & 124 & 154 & 80.52 \\
\hline Vaginal delivery & 30 & 154 & 19.48 \\
\hline Chronic diseases & 21 & 84 & 25.00 \\
\hline Obstetric complications & 18 & 52 & 34.62 \\
\hline Gestational hypertension & 11 & 82 & 13.41 \\
\hline $\begin{array}{l}\text { Gestational diabetes } \\
\text { mellitus }\end{array}$ & 4 & 34 & 11.76 \\
\hline Anemia & 6 & 19 & 31.58 \\
\hline Preeclampsia & 4 & 31 & 12.90 \\
\hline \multicolumn{4}{|l|}{ Clinical symptoms } \\
\hline Fever & 124 & 210 & 59.05 \\
\hline Cough & 115 & 210 & 54.76 \\
\hline Myalgia & 19 & 149 & 12.75 \\
\hline Sore throat & 4 & 136 & 2.94 \\
\hline Physical discomfort & 12 & 56 & 21.43 \\
\hline Shortness of breath & 20 & 168 & 11.90 \\
\hline Diarrhea & 8 & 158 & 5.06 \\
\hline Headache & 16 & 141 & 11.35 \\
\hline Postpartum fever & 25 & 98 & 25.51 \\
\hline \multicolumn{4}{|l|}{ Laboratory results } \\
\hline $\begin{array}{l}\text { Lymphocytes count } \\
<1 \times 10^{9} \text { cells per } \mathrm{L}\end{array}$ & 57 & 140 & 40.71 \\
\hline $\begin{array}{l}\text { The white blood cells } \\
\text { count } \\
>10 \times 10^{9} \text { cells per }\end{array}$ & 21 & 124 & 16.84 \\
\hline $\begin{array}{l}\text { Platelet count } \\
<100 \times 10^{9} \text { per } \mathrm{L}\end{array}$ & 5 & 124 & 4.03 \\
\hline $\begin{array}{l}\text { Transaminase concentra- } \\
\text { tion } \\
>40 \mathrm{U} / \mathrm{L}\end{array}$ & 26 & 104 & 25.00 \\
\hline $\begin{array}{l}\text { Myocardial enzyme } \\
>190 \mathrm{IU} / \mathrm{L}\end{array}$ & 4 & 9 & 44.44 \\
\hline $\begin{array}{l}\text { C-reactive protein concen- } \\
\text { tration } \\
>10 \mathrm{mg} / \mathrm{L}\end{array}$ & 83 & 129 & 64.34 \\
\hline $\begin{array}{l}\text { IL-6 } \\
\geq 7 \mathrm{pg} / \mathrm{mL}\end{array}$ & 5 & 5 & 100.00 \\
\hline $\begin{array}{l}\text { D-dimer } \\
>500 \mu \mathrm{g} / \mathrm{L}\end{array}$ & 92 & 112 & 82.14 \\
\hline $\begin{array}{l}\text { Procalcitonin } \\
\geq 0.25 \mathrm{ng} / \mathrm{mL}\end{array}$ & 5 & 13 & 38.46 \\
\hline \multicolumn{4}{|l|}{ Chest CT imaging } \\
\hline $\begin{array}{l}\text { Typical imaging manifes- } \\
\text { tations }\end{array}$ & 135 & 139 & 97.12 \\
\hline \multicolumn{4}{|l|}{ Treatment } \\
\hline Oxygen support & 67 & 112 & 59.82 \\
\hline Mechanical ventilation & 7 & 135 & 5.19 \\
\hline \multicolumn{4}{|l|}{ Clinical classification } \\
\hline Critical type & 7 & 175 & 4.00 \\
\hline Severe type & 14 & 175 & 8.00 \\
\hline Moderate type & 144 & 175 & 82.29 \\
\hline
\end{tabular}

Table 2 (continued)

\begin{tabular}{lclr}
\hline & Case numbers & Total numbers & $\%$ \\
\hline Asymptomatic & 10 & 175 & 5.71 \\
Outcome & & & \\
Get well/discharge & 229 & 230 & 99.57 \\
Death & 1 & 230 & 0.43 \\
\hline
\end{tabular}

women had moderate disease. Ten $(5.71 \%)$ pregnant women were asymptomatic. A critically ill pregnant woman with 35 weeks of pregnancy had septic shock, respiratory failure, and emergency cesarean section, and the newborn died of intrauterine asphyxia. This pregnant woman received invasive mechanical ventilation, extracorporeal membrane oxygenation (ECMO), continuous renal replacement therapy (CRRT), and convalescent plasma and ultimately survived $[22,29]$. At present, the only deceased case is a 27 -year-old woman with 30 weeks of gestation, who deteriorated rapidly and underwent invasive mechanical ventilation due to respiratory distress; the patient died of multiorgan failure. Her fetus was born with an Apgar score of 0 and without reaction to the neonatal cardiopulmonary resuscitation protocol [20]. Most of the pregnant women with COVID-19 were getting better or were discharged.

\section{Perinatal characteristics and outcomes of newborns}

A total of 156 newborns were born (Table 3). A total of 97.06\% of newborns had a 1-min Apgar score above 8. All live newborns had 5-min Apgar scores above 8. A total of $24.74 \%$ of newborns were premature (24/97), and 5.45\% of newborns had fetal distress (3/55). A total of $8.49 \%$ of newborns had premature rupture of membranes (9/106). Only one newborn received mechanical ventilation. Two newborns died unfortunately, including a newborn who died of intrauterine asphyxia [22, 29]; the other deceased newborn

Table 3 Perinatal characteristics and outcomes of newborns

\begin{tabular}{lrrr}
\hline & Case numbers & Total numbers & $\%$ \\
\hline Apgar score $(1 \mathrm{~min}) \geq 8$ & 99 & 102 & 97.06 \\
Apgar score $(5 \mathrm{~min}) \geq 8$ & 118 & 120 & 98.33 \\
Premature & 24 & 97 & 24.74 \\
Fetal distress & 3 & 55 & 5.45 \\
Premature rupture of mem- & 9 & 106 & 8.49 \\
$\quad$ branes & & & \\
Mechanical ventilation & 1 & 42 & 2.38 \\
Oxygen therapy & 0 & 10 & 0.00 \\
Get well/discharge & 154 & 156 & 98.72 \\
Death & 2 & 156 & 1.28 \\
\hline
\end{tabular}


was born with an Apgar score of 0 and did not react to the neonatal cardiopulmonary resuscitation protocol [20].

\section{Possibility of vertical transmission}

These 154 mothers with COVID-19 gave birth to 156 newborns (Table 4). The results of the nucleic acid test of SARSCoV-2 in 128 newborns were reported, including 123 newborns' negative throat swab tests and five positive tests [14, $15,30]$. Five infants who tested positive for SARS-CoV-2 were delivered by cesarean section. Elevated concentration of IgM and IgG against SARS-CoV-2 were detected in eight newborns whose throat swab test were negative [21, $31,32]$, three of which had elevations in both IgM and IgG against SARS-CoV-2. Three newborns had elevated IgG but normal IgM. Interleukin 6 was also abnormally elevated in these six newborns. RT-PCR tests of SARS-CoV-2 of the vaginal secretions $(n=13)$, breast milk $(n=25)$, amniotic fluid ( $n=32$ ), placental blood ( $n=35$ ), and placental tissues $(n=9)$, specimens that are associated with vertical transmission, were all negative.

\section{Discussion}

\section{Main findings}

The results of this systematic review showed that the clinical manifestations of pregnant women with COVID19 were similar to those of general COVID-19 patients [33], including fever, cough, myalgia, shortness of breath, and diarrhea. The common laboratory changes of patients included lymphopenia, leukocytosis, decreased platelet counts, supraphysiological concentrations of transaminase, C-reactive protein, and D-dimer. The majority of chest CT scans showed typical imaging manifestations of COVID -19 pneumonia.

Common obstetric complications, such as gestational hypertension, preeclampsia, and gestational diabetes mellitus, may affect the outcomes. More than $80 \%$ of the patients were mild cases. Asymptomatic infections were reported in pregnant women. The proportion of mechanical ventilation was $5.19 \%$, which was slightly lower than that of the general population [33]. The case-fatality rate $(0.43 \%)$ is lower than the mortality of COVID-19 patients reported by World Health Organization $(6.80 \%)$ and the Chinese Center for Disease Control and Prevention $(2.29 \%)[34,35]$ and similar to the overall maternal mortality rate worldwide (1 in 180) [36].

Most patients were in the third trimester of pregnancy. A total of 124 (80.52\%) patients underwent a cesarean section. The most common adverse pregnancy outcome, premature delivery, occurred in up to $24.74 \%$ of pregnant women. Premature rupture of membranes, fetal distress, and even fetal death were also reported.

There was more evidence for vertical transmission of COVID-19. Under strict protection during delivery and postpartum isolation measures, $3.91 \%(5 / 128)$ of newborns were tested positive for SARS-CoV-2 nucleic acid, and elevation of IgM against SARS-CoV-2 was found in $3 / 8$ newborns with negative of SARS-CoV-2 nucleic acid results. However, more details, including nucleic acid test results of vaginal secretions, breast milk, amniotic fluid, placenta tissues, and cord blood, did not support vertical transmission. In particular, newborns with a positive SARS-CoV-2 nucleic acid test or elevated serum antibody were all delivered by cesarean section. From the perspectives of disinfection and protection, breastfeeding may not cause neonatal infection.
Table 4 Newborn SARS-CoV-2 nucleic acid detection and other specimens related

\begin{tabular}{lccl}
\hline & Case numbers & Total numbers & $\%$ \\
\hline Test for SARS-CoV-2 by nucleic acid & 128 & 156 & 82.05 \\
Negative result & 123 & 128 & 96.09 \\
Positive result & 5 & 128 & 3.91 \\
Via vaginal delivery & 0 & 5 & 0 \\
Via cesarean delivery & 5 & 5 & 100 \\
Test for SARS-CoV-2 by antibody & 8 & 8 & 100 \\
IgG increased and IgM increased & 3 & 8 & 37.5 \\
IgG increased and IgM normal & 3 & 8 & 37.5 \\
Vaginal secretions test negative & 13 & 13 & 100.00 \\
Breast milk test negative & 25 & 25 & 100.00 \\
Amniotic fluid test negative & 32 & 32 & 100.00 \\
Cord blood test negative & 35 & 35 & 100.00 \\
Placenta tissues test negative & 9 & 9 & 100.00 \\
\hline
\end{tabular}




\section{Strengths and limitations}

Several reviews have summarized the situation of pregnant women infected with COVID-19 [37-39], however, knowledge needs to be summarized in a timely manner. The strengths are as follows. First, the databases were comprehensive; therefore, we enrolled as many timely articles as possible. Second, we carefully and strictly reviewed articles to remove as much duplicated data as possible. Finally, we summarized comprehensive details related to vertical transmission.

One of our limitations is the inclusion of case reports, which may be inclined to report more severe cases. Another limitation is that all included articles were retrospective studies. Prospective studies will lead to a better understanding of pregnant women with COVID-19.

\section{Interpretation}

Pregnant women are at high risk of infection or may be already infected with COVID-19. Psychological stress and viral infections are both risk factors for miscarriage [40]. The psychological pressure brought by COVID-19 has driven several patients to terminate their pregnancies [24]. More information about pregnant women with COVID-19 is urgently needed to relieve their anxiety and guide them to make beneficial decisions.

According to our results, most patients are asymptomatic or mildly ill. They come to the hospital because of their pregnancy and the need for medical care for childbirth. Then, the detection of coronavirus infection reveals that these patients are in an early stage of infection, with milder symptoms, or may even be asymptomatic or have very few symptoms, which may be one of the contributors to their favorable prognosis. However, asymptomatic infections do not seem to be a minority. A report of new cases indicates that up to four-fifths of people are asymptomatic [41], and $32.6 \%$ of pregnant women with COVID-19 had no symptoms in a New York hospital [25]. Isolation at home and travel restrictions protect people from infection but disrupt routine prenatal examinations and the discovery of abnormal pregnancies in time. Pregnant women are in states of anxiety and worry regarding issues such as the epidemic's status, the impacts on maternal and child health, the safety of CT examination, and treatment prognosis for the fetus and the mother [42]. Pregnant women may be worried about being infected and may demand psychological consultation [43]. We agree that measures such as pregnant women being screened and followed up, being offered more flexible birth inspection strategies [44], and receiving more concern for their mental health are required [45].

SARS infection during pregnancy has been correlated with a high incidence of spontaneous abortion and premature delivery $[37,46]$. Similar phenomena have also been observed in pregnant women with COVID-19. In three placental pathology reports, no pathological alternation of villitis and chorioamnionitis was observed [47]. To understand the underlying mechanism, more placental pathological reports, especially those with adverse neonatal outcomes, are needed.

Regarding delivery mode, cesarean section and vaginal delivery have their respective short- and long-term advantages and disadvantages $[48,49]$. During vaginal delivery, amniotic fluid, vaginal bleeding, and vaginal discharge increase the difficulty of infection control. Cesarean section seems to benefit both patients and medical staff [50], but there is no clear evidence on whether vaginal delivery or cesarean section is more beneficial [51]. This review shows that more pregnant women with COVID-19 delivered by cesarean section instead of via the vagina. On the one hand, a high incidence of intraoperative hypotension has been noted in pregnant COVID-19 patients during cesarean section [52, 53]; on the other hand, no evidence of vertical transmission was observed with vaginal delivery.

About a decade ago, the limited publications on pregnant women with SARS reported no evidence of vertical transmission [3, 54]. Here, we included some single-center studies to summarize the possibility of vertical transmission of COVID-19 [30, 31, 47, 55-58]. Although strict isolation measures are taken, a few newborns still show positive results on the SARS-CoV-2 nucleic acid test. Possible mechanisms for vertical transmission (from the mother to the fetus or newborn) mainly include: transplacental transmission after the virus infects the placenta, intrapartum transmission via ingestion or aspiration of cervical vaginal secretions during delivery, and postpartum transmission by breastfeeding [59]. Evidence supporting intrauterine transmission is the discovery of elevated $\operatorname{IgM}$ and $\mathrm{IgG}$ against SARS-CoV-2 in infants [31, 32]. Unlike $\mathrm{IgG}, \operatorname{IgM}$ is not usually transferred from mother to fetus because of its larger macromolecular structure. Therefore, it is probably produced by the fetus after infection. Vertical transmission could be considered when both $\operatorname{IgM}$ and $\mathrm{IgG}$ are elevated conservatively. Paradoxically, angiotensin-converting enzyme 2(ACE 2), the receptor of SARS-CoV-2, is poorly expressed in various cell types at the maternal-fetal interface [60], and SARS-CoV-2 was undetected in the placenta histopathology of infected parturients [47]. Though the evidence is inconclusive, no vertical transmission phenomenon or evidence of the vaginal delivery process has been found. According to the cautious advice of experts [61,62], the vast majority of newborns were separated from their COVID-19 confirmed mothers and fed formula milk powder. The WHO recommends that mothers can share a room with their infants and provide breast feeding after SARS-CoV-2 testing is 
negative in their breast milk [63]. Mothers should wear masks, practice hand hygiene [64], and disinfect all containers of expressed human milk [65].

Only $6.5 \%$ of the newborns with negative PCR results were also tested for serum antibodies against SARSCoV-2. It will not be representative and convincing to calculate the vertical transmission probability with such a small sample size and possible biased data. One study showed that the sensitivity of RT-PCR to detect viral nucleic acids was only $71 \%$ [66]. Collecting a variety of samples, in addition to nasopharyngeal swabs, can improve the positive detection rate [67]. Serum antibodies against SARS-CoV-2 should be tested more frequently and multiple samples should be included in pathogenic testing.

\section{Conclusion}

This study included 230 pregnant women, of which 154 delivered 156 newborns, and summarized the clinical characteristics and maternal and neonatal outcomes of pregnant women with COVID-19. Most patients had a mild illness. Symptoms, chest CT imaging, and laboratory tests of infected pregnant women were similar to those of the overall patients with COVID-19. Cesarean section was more common than vaginal delivery in COVID-19 parturients. Worries about infection led to several abortions. Premature delivery was the most common adverse pregnancy outcome. The maternal mortality rate was $0.43 \%$, and the neonatal mortality rate was $1.28 \%$. The vertical transmission rate calculated by the PCR-proven COVID-19 test was 3.91\%, and all five newborns with positive results were delivered by cesarean dissection. Other related findings we summarized do not provide more evidence for the vertical transmission of SARS-CoV-2. Serum antibodies against SARS-CoV-2 should be tested more frequently, and multiple samples should be included in pathogenic testing.

Acknowledgements Thanks to the medical staff in the epidemic. Patients and the tender newborns are protected by their extraordinary courage, high sense of responsibility, superb medical skills and tireless work.

Author contributions QG and JC: conceptualized the study design. JC and WG: conducted the literature search, screened references and extracted data. WG: conducted data analysis. JC and WG: wrote the first draft of the article. QG: contributed to revising the manuscript.

Funding The study was supported by the National Natural Science Foundation of China (81772787, and 81873452). The sponsors of the study had no role in the study design, data collection, data analysis, data interpretation, or writing of the manuscript.

Availability of data and materials Data and material were available.

\section{Compliance with ethical standards}

Conflict of interest The authors report no conflict of interest.

Ethical approval This study is a systematic review, we comply with ethical standards when we do this research, and ethical approval is not applicable.

Informed consent This study is a systematic review, therefore informed consent is not applicable.

Open Access This article is licensed under a Creative Commons Attribution 4.0 International License, which permits use, sharing, adaptation, distribution and reproduction in any medium or format, as long as you give appropriate credit to the original author(s) and the source, provide a link to the Creative Commons licence, and indicate if changes were made. The images or other third party material in this article are included in the article's Creative Commons licence, unless indicated otherwise in a credit line to the material. If material is not included in the article's Creative Commons licence and your intended use is not permitted by statutory regulation or exceeds the permitted use, you will need to obtain permission directly from the copyright holder. To view a copy of this licence, visit http://creativecommons.org/licenses/by/4.0/.

\section{References}

1. Wu T, Kang SC, Feng W, Fu H, Zhu XH, Wang XJ, Dai PJ, Wang TH, Bai H, Xi R, Zhang Q, Xue X, Xiang DW (2020) Biological characters analysis of COVID-19 patient accompanied with aplastic anemia. Zhonghua xue ye xue za zhi = Zhonghua xueyexue zazhi 41:E003. https://doi.org/10.3760/cma.j.i ssn.0253-2727.2020.0003

2. Tan EK, Tan EL (2013) Alterations in physiology and anatomy during pregnancy. Best Pract Res Clin Obstet Gynaecol 27(6):791-802. https://doi.org/10.1016/j.bpobgyn.2013.08.001

3. Schwartz DA, Graham AL (2020) Potential maternal and infant outcomes from (Wuhan) coronavirus 2019-nCoV infecting pregnant women: lessons from SARS, MERS, and other human coronavirus infections. Viruses. https://doi.org/10.3390/v12020194

4. Liberati A, Altman DG, Tetzlaff J, Mulrow C, Gøtzsche PC, Ioannidis JP, Clarke M, Devereaux PJ, Kleijnen J, Moher D (2009) The PRISMA statement for reporting systematic reviews and meta-analyses of studies that evaluate health care interventions: explanation and elaboration. PLoS Med 6(7):e1000100. https:// doi.org/10.1371/journal.pmed.1000100

5. Murad MH, Sultan S, Haffar S, Bazerbachi F (2018) Methodological quality and synthesis of case series and case reports. BMJ Evid Based Med 23(2):60-63. https://doi.org/10.1136/bmjebm-2017110853

6. Yu Zengyuan XW, Yingjun F, Qiongdan B, Mingli J, Jing W, Peng Li, Huiyan Y, Wenqing K (2020) A case report of neonatal severe novel coronavirus transshipment therapy. Chin J Evid Based Pediatr 15(1):37-41 (in Chinese)

7. Zhao Ruihong WH, Kaijin X, Jifang S (2020) Pregnancy complicated with novel coronavirus: a case report. Zhejiang Med J 42(4):303-304+317 (in Chinese)

8. Chen S, Liao E, Shao Y (2020) Clinical analysis of pregnant women with 2019 novel coronavirus pneumonia. J Med Virol. https://doi.org/10.1002/jmv.25789

9. Lee DH, Lee J, Kim E, Woo K, Park HY, An J (2020) Emergency cesarean section on severe acute respiratory syndrome coronavirus 
2 (SARS- CoV-2) confirmed patient. Korean J Anesthesiol. https ://doi.org/10.4097/kja.20116

10. Li N, Han L, Peng M, Lv Y, Ouyang Y, Liu K, Yue L, Li Q, Sun G, Chen L, Yang L (2020) Maternal and neonatal outcomes of pregnant women with COVID-19 pneumonia: a case-control study. medRxiv. https://doi.org/10.1101/2020.03.10.20033605

11. Li Y, Zhao R, Zheng S, Chen X, Wang J, Sheng X, Zhou J, Cai H, Fang Q, Yu F, Fan J, Xu K, Chen Y, Sheng J (2020) Lack of vertical transmission of severe acute respiratory syndrome coronavirus 2, China. Emerg Infect Dis. https://doi.org/10.3201/eid26 06.200287

12. Wang X, Zhou Z, Zhang J, Zhu F, Tang Y, Shen X (2020) A case of 2019 novel coronavirus in a pregnant woman with preterm delivery. Clin Infect Dis 71(15):844-846. https://doi.org/10.1093/ $\mathrm{cid} / \mathrm{ciaa} 200$

13. Zambrano LI, Fuentes-Barahona IC, Bejarano-Torres DA, Bustillo C, Gonzales G, Vallecillo-Chinchilla G, Sanchez-Martinez FE, Valle-Reconco JA, Sierra M, Bonilla-Aldana DK, CardonaOspina JA, Rodriguez-Morales AJ (2020) A pregnant woman with COVID-19 in Central America. Travel Med Infect Dis. https://doi. org/10.1016/j.tmaid.2020.101639

14. Zeng L, Xia S, Yuan W, Yan K, Xiao F, Shao J, Zhou W (2020) Neonatal early-onset infection with SARS-CoV-2 in 33 neonates born to mothers with COVID-19 in Wuhan, China. JAMA Pediatrics. https://doi.org/10.1001/jamapediatrics.2020.0878

15. Li M, Xu M, Zhan W, Han T, Zhang G, Lu Y (2020) The first case report of 2019 mother-to-child infection in novel coronavirus in Xinyang City, Henan Province. Chin J Infect Dis. https://doi. org/10.3760/cma.j.issn.1000-6680.2020.0007 (in Chinese)

16. Zhao Yiwei LZ, Xujie M, Xiaole J, Wei Z (2020) A case of neonatal dyspnea caused by mother delivery in novel coronavirus. Chin J Neonatol. https://doi.org/10.3760/cma.j.i ssn.2096-2932.2020.0001 (in Chinese)

17. Zhou R, Chen Y, Lin C, Li H, Cai X, Cai Z, Lin G (2020) A case of asymptomatic pregnant women with pulmonary imaging changes infected by novel coronavirus. Chin J Perinat Med 3:E006-E006. https://doi.org/10.3760/cma.j.cn113903-20200 220-00134 (in Chinese)

18. Zhuang S, Guo J, Cao Y, Chen H, Xu D, Li J, Zhang Y (2020) A case of perinatal novel coronavirus infection. Chin J Perinat Med 23(2):85-90. https://doi.org/10.3760/cma.j.i ssn.1007-9408.2020.02.003 (in Chinese)

19. Kalafat E, Yaprak E, Cinar G, Varli B, Ozisik S, Uzun C, Azap A, Koc A (2020) Lung ultrasound and computed tomographic findings in pregnant woman with COVID-19. Ultrasound Obstet Gynecol. https://doi.org/10.1002/uog.22034

20. Karami P, Naghavi M, Feyzi A, Aghamohammadi M, Novin MS, Mobaien A, Qorbanisani M, Karami A, Norooznezhad AH (2020) Mortality of a pregnant patient diagnosed with COVID-19: a case report with clinical, radiological, and histopathological findings. Travel Med Infect Dis. https://doi.org/10.1016/j.tmaid.2020.10166 5

21. Xiong X, Wei H, Zhang Z, Chang J, Ma X, Gao X, Chen Q, Pang Q (2020) Vaginal delivery report of a healthy neonate born to a convalescent mother with COVID-19. J Med Virol. https://doi. org/10.1002/jmv. 25857

22. Zhang B, Liu S, Tan T, Huang W, Dong Y, Chen L, Chen Q, Zhang L, Zhong Q, Zhang X, Zou Y, Zhang S (2020) Treatment With convalescent plasma for critically Ill patients with SARS-CoV-2 infection. Chest. https://doi.org/10.1016/j.chest .2020.03.039

23. Huang Liqun WJ, Chumei X, Dianxing S (2020) Successful treatment of the first pregnancy with severe new coronavirus pneumonia. Med Pharm J Chin People's Lib Army. https://doi. org/10.3969/j.issn.2095-140X.2020.04.001 (in Chinese)
24. Chen L, Li Q, Zheng D, Jiang H, Wei Y, Zou L, Feng L, Xiong G, Sun G, Wang H, Zhao Y, Qiao J (2020) Clinical characteristics of pregnant women with Covid-19 in Wuhan, China. N Engl J Med. https://doi.org/10.1056/NEJMc2009226

25. Breslin N, Baptiste C, Gyamfi-Bannerman C, Miller R, Martinez R, Bernstein K, Ring L, Landau R, Purisch S, Friedman AM, Fuchs K, Sutton D, Andrikopoulou M, Rupley D, Sheen JJ, Aubey J, Zork N, Moroz L, Mourad M, Wapner R, Simpson LL, D'Alton ME, Goffman D (2020) COVID-19 infection among asymptomatic and symptomatic pregnant women: two weeks of confirmed presentations to an affiliated pair of New York City hospitals. Am J Obstet Gynecol. https://doi.org/10.1016/j.ajogmf.2020.100118

26. Nishiga M, Wang DW, Han Y, Lewis DB, Wu JC (2020) COVID19 and cardiovascular disease: from basic mechanisms to clinical perspectives. Nat Rev Cardiol. https://doi.org/10.1038/s4156 9-020-0413-9

27. Liu F, Li L, Xu M, Wu J, Luo D, Zhu Y, Li B, Song X, Zhou $X$ (2020) Prognostic value of interleukin-6, C-reactive protein, and procalcitonin in patients with COVID-19. J Clin Virol 127:104370. https://doi.org/10.1016/j.jcv.2020.104370

28. Herold T, Jurinovic V, Arnreich C, Lipworth BJ, Hellmuth JC, von Bergwelt-Baildon M, Klein M, Weinberger T (2020) Elevated levels of IL-6 and CRP predict the need for mechanical ventilation in COVID-19. J Allergy Clin Immunol 146(1):128-136.e124. https://doi.org/10.1016/j.jaci.2020.05.008

29. He S, Wang D, Chi R, Ding D, Yu Y, He M, Li W, Chi C, Shi M (2020) A case of critical novel coronavirus in late pregnancy. Chin J Perinat Med. https://doi.org/10.3760/cma.j.cn113903-2020022800171 (in Chinese)

30. Nie R, Wang S-S, Yang Q, Fan C-F, Liu Y-L, He W-C, Jiang M, Liu C-C, Zeng W-J, Wu J-L, Oktay K, Feng L, Jin L (2020) Clinical features and the maternal and neonatal outcomes of pregnant women with coronavirus disease 2019. medRxiv. https://doi. org/10.1101/2020.03.22.20041061

31. Dong L, Tian J, He S, Zhu C, Wang J, Liu C, Yang J (2020) Possible vertical transmission of SARS-CoV-2 from an infected mother to her newborn. JAMA. https://doi.org/10.1001/jama.2020.4621

32. Zeng H, Xu C, Fan J, Tang Y, Deng Q, Zhang W, Long X (2020) Antibodies in infants born to mothers with COVID-19 pneumonia. JAMA. https://doi.org/10.1001/jama.2020.4861

33. Guan WJ, Ni ZY, Hu Y, Liang WH, Ou CQ, He JX, Liu L, Shan H, Lei CL, Hui DSC, Du B, Li LJ, Zeng G, Yuen KY, Chen RC, Tang CL, Wang T, Chen PY, Xiang J, Li SY, Wang JL, Liang ZJ, Peng YX, Wei L, Liu Y, Hu YH, Peng P, Wang JM, Liu JY, Chen Z, Li G, Zheng ZJ, Qiu SQ, Luo J, Ye CJ, Zhu SY, Zhong NS (2020) Clinical characteristics of coronavirus disease 2019 in China. N Engl J Med. https://doi.org/10.1056/NEJMoa2002032

34. Wu Z, McGoogan JM (2020) Characteristics of and important lessons from the coronavirus disease 2019 (COVID-19) outbreak in China: summary of a report of 72314 cases from the Chinese center for disease control and prevention. JAMA. https://doi. org/10.1001/jama.2020.2648

35. Wu Y, Wang T, Guo C, Zhang D, Ge X, Huang Z, Zhou X, Li Y, Peng Q, Li J (2020) Plasminogen improves lung lesions and hypoxemia in patients with COVID-19. QJM. https://doi. org/10.1093/qjmed/hcaa121

36. WHO U, UNFPA, World Bank Group and the United Nations Population Division (2015) Trends in maternal mortality: 1990 to 2015. Estimates by WHO, UNICEF, UNFPA, World Bank Group and the United Nations Population Division. https://www.who. int/reproductivehealth/publications/monitoring/maternal-morta lity-2015/en/.

37. Di Mascio D, Khalil A, Saccone G, Rizzo G, Buca D, Liberati M, Vecchiet J, Nappi L, Scambia G, Berghella V, D’Antonio F (2020) Outcome of coronavirus spectrum infections (SARS, MERS, COVID 1-19) during pregnancy: a systematic review and 
meta-analysis. Am J Obstet Gynecol. https://doi.org/10.1016/j. ajogmf.2020.100107

38. Zaigham M, Andersson O (2020) Maternal and perinatal outcomes with COVID-19: a systematic review of 108 pregnancies. Acta Obstet Gynecol Scand. https://doi.org/10.1111/aogs.13867

39. Gajbhiye R, Modi D, Mahale S (2020) Pregnancy outcomes, newborn complications and maternal-fetal transmission of SARSCoV-2 in women with COVID-19: a systematic review. medRxiv. https://doi.org/10.1101/2020.04.11.20062356

40. Giakoumelou S, Wheelhouse N, Cuschieri K, Entrican G, Howie SE, Horne AW (2016) The role of infection in miscarriage. Hum Reprod Update 22(1):116-133. https://doi.org/10.1093/humupd/ dmv041

41. Day M (2020) Covid-19: four fifths of cases are asymptomatic, China figures indicate. BMJ (Clin Res Ed) 369:m1375. https://doi. org/10.1136/bmj.m1375

42. Xingying L, Abduklim N, Jinlong S, Xiaohua Z, Sheena L, Weiyi C, Fengyun Y, Liandi S, Yongfen L, Xiaoling Z, Cui W, Zhangyanling HJ (2020) Investigation on maternal health care needs under novel coronavirus epidemic situation. Chin J Woman Child Health Res 31(2):141-146. https://doi.org/10.3969/j/issn.16735293.2020.02.002 (in Chinese)

43. Du L, Gu Y, Cui M, Li W, Wang J, Zhu L, Xu B (2020) Investigation on health care needs of 2002 pregnant women in shanghai during the epidemic period in novel coronavirus. Chin J Obstet Gynecol. https://doi.org/10.3760/cma.j.cn112141-2020021800112 (in Chinese)

44. Zhang Cong SQ, Ling F (2020) Pregnant women's new coronavirus infection during the epidemic prevention Internet "cloud inspection" strategy. Prog Obstet Gynecol 29(3):165-166. https ://doi.org/10.13283/j.cnki.xdfckjz.2020.03.003 (in Chinese)

45. Topalidou A, Thomson G, Downe S (2020) COVID-19 and maternal mental health: are we getting the balance right? medRxiv. https://doi.org/10.1101/2020.03.30.20047969

46. Wong SF, Chow KM, Leung TN, Ng WF, Ng TK, Shek CC, Ng PC, Lam PW, Ho LC, To WW, Lai ST, Yan WW, Tan PY (2004) Pregnancy and perinatal outcomes of women with severe acute respiratory syndrome. Am J Obstet Gynecol 191(1):292-297. https://doi.org/10.1016/j.ajog.2003.11.019

47. Chen S, Huang B, Luo DJ, Li X, Yang F, Zhao Y, Nie X, Huang BX (2020) Pregnant women with new coronavirus infection: a clinical characteristics and placental pathological analysis of three cases. Zhonghua bing li xue za zhi $=$ Chin J Pathol 49:E005. https ://doi.org/10.3760/cma.j.cn112151-20200225-00138

48. Sachs BP, McCarthy BJ, Rubin G, Burton A, Terry J, Tyler CW Jr (1983) Cesarean section. Risk and benefits for mother and fetus. JAMA 250(16):2157-2159. https://doi.org/10.1001/ jama.250.16.2157

49. Keag OE, Norman JE, Stock SJ (2018) Long-term risks and benefits associated with cesarean delivery for mother, baby, and subsequent pregnancies: systematic review and meta-analysis. PLoS Med 15(1):e1002494. https://doi.org/10.1371/journal.pmed.10024 94

50. National centre for management and control of obstetric medical quality (2020) Suggestions on delivery management of pregnant women with COVID-19. Zhonghua fu chan ke za zhi 55(3):150152. https://doi.org/10.3760/cma.j.cn112141-20200224-00128 (in Chinese)

51. Chien $P$ (2020) The consequences of the COVID-19 pandemic. BJOG Int J Obstet Gynaecol 127(8):917-918. https://doi. org/10.1111/1471-0528.16299

52. Zhang Y, Chen R, Wang J, Gong Y, Zhou Q, Cheng H-h, Xia Z-y, Chen X, Meng Q-t, Ma D (2020) Anaesthetic managment and clinical outcomes of parturients with COVID-19: a multicentre, retrospective, propensity score matched cohort study. medRxiv. https://doi.org/10.1101/2020.03.24.20042176
53. Chen R, Zhang Y, Huang L, Cheng B-h, Xia Z-y, Meng Q-t (2020) Safety and efficacy of different anesthetic regimens for parturients with COVID-19 undergoing Cesarean delivery: a case series of 17 patients. Canad J Anesth. https://doi.org/10.1007/s12630-02001630-7

54. Ksiezakowska K, Laszczyk M, Wilczyński J, Nowakowska D (2008) SARS-CoV infection and pregnancy. Ginekol Pol 79(1):47-50

55. Chen H, Guo J, Wang C, Luo F, Yu X, Zhang W, Li J, Zhao D, Xu D, Gong Q, Liao J, Yang H, Hay W, Zhang Y (2020) Clinical characteristics and intrauterine vertical transmission potential of COVID-19 infection in nine pregnant women: a retrospective review of medical records. Lancet 395(10226):809-815. https:// doi.org/10.1016/s0140-6736(20)30360-3

56. Fan C, Lei D, Fang C, Li C, Wang M, Liu Y, Bao Y, Sun Y, Huang J, Guo Y, Yu Y, Wang S (2020) Perinatal transmission of COVID19 associated SARS-CoV-2: should we worry? Clin Infect Dis. https://doi.org/10.1093/cid/ciaa226

57. Khan S, Peng L, Siddique R, Nabi G, Nawsherwan XM, Liu J, Han $G$ (2020) Impact of COVID-19 infection on pregnancy outcomes and the risk of maternal-to-neonatal intrapartum transmission of COVID-19 during natural birth. Infect Control Hosp Epidemiol 41(6):748-750. https://doi.org/10.1017/ice.2020.84

58. Liu D, Li L, Wu X, Zheng D, Wang J, Yang L, Zheng C (2020) Pregnancy and perinatal outcomes of women with coronavirus disease (COVID-19) pneumonia: a preliminary analysis. AJR Am J Roentgenol. https://doi.org/10.2214/ajr.20.23072

59. Silasi M, Cardenas I, Kwon JY, Racicot K, Aldo P, Mor G (2015) Viral infections during pregnancy. Am J Reprod Immunol 73(3):199-213. https://doi.org/10.1111/aji.12355

60. Zheng Q-L, Duan T, Jin L-P (2020) Single-cell RNA expression profiling of ACE2 and AXL in the human maternal-Fetal interface. Reprod Dev Med 4(1):7-10. https://doi.org/10.4103/20962924.278679

61. Li F, Feng ZC, Shi Y (2020) Proposal for prevention and control of the 2019 novel coronavirus disease in newborn infants. Arch Dis Child Fetal Neonatal Ed. https://doi.org/10.1136/archdischi ld-2020-318996

62. Favre G, Pomar L, Qi X, Nielsen-Saines K, Musso D, Baud D (2020) Guidelines for pregnant women with suspected SARSCoV-2 infection. Lancet Infect Dis. https://doi.org/10.1016/s1473 $-3099(20) 30157-2$

63. WHO Protecting, promoting and supporting breastfeeding in facilities providing maternity and newborn services Guideline. https://www.who.int/nutrition/publications/guidelines/breastfeed ing-facilities-maternity-newborn/en/

64. CDC Considerations for Inpatient Obstetric Healthcare Settings.

65. Marinelli KA, Lawrence RM (2020) Safe handling of containers of expressed human milk in all settings during the SARSCoV-2 (COVID-19) pandemic. J Hum Lactation. https://doi. org/10.1177/0890334420919083

66. Fang Y, Zhang H, Xie J, Lin M, Ying L, Pang P, Ji W (2020) Sensitivity of chest CT for COVID-19: comparison to RT-PCR. Radiology. https://doi.org/10.1148/radiol.2020200432

67. Wu J, Liu J, Li S, Peng Z, Xiao Z, Wang X, Yan R, Luo J (2020) Detection and analysis of nucleic acid in various biological samples of COVID-19 patients. Travel Med Infect Dis. https://doi. org/10.1016/j.tmaid.2020.101673

Publisher's Note Springer Nature remains neutral with regard to jurisdictional claims in published maps and institutional affiliations. 